\title{
Prevalence of Sleep Disturbance and correlates in Chinese Older Adults with type 2 diabetes
}

\section{Yu-Xing Gong}

Southern Medical University

\section{Cai-Lan Hou}

Southern Medical University

\section{Shi-Bin Wang}

Guangdong General Hospital \& Guangdong Academy of Medical Sciences

\section{Fei Wang}

Guangdong General Hospital \& Guangdong Academy of Medical Sciences

\section{Zhuo-Hui Huang}

Guangdong General Hospital \& Guangdong Academy of Medical Sciences

Jing-Jing Yang

Guangdong General Hospital \& Guangdong Academy of Medical Sciences

Fu-jun Jia ( $\square$ jiafujun@126.com )

Southern Medical University

\section{Research Article}

Keywords: sleep disturbance, type 2 diabetes, depression, quality of life

Posted Date: October 29th, 2021

DOI: https://doi.org/10.21203/rs.3.rs-886317/v1

License: (c) (i) This work is licensed under a Creative Commons Attribution 4.0 International License. Read Full License 


\section{Abstract \\ Objective}

To examine the prevalence of sleep disturbances, the socio-demographic and clinical correlates in Chinese older adults with type 2 diabetes (T2DM).

\section{Methods}

A cross-sectional survey of 195 patients with T2DM was conducted using standardized instruments.

\section{Results}

The prevalence of any type of sleep disturbances was $38.5 \%$, the incidence of DIS, DMS, and EMA were $23.6 \%, 25.6 \%$ and $26.2 \%$, respectively. No statistically significant difference was observed in socio-demographic data between participants with and without sleep disturbances except age. Sleep disturbances were associated with more severe depressive symptoms and lower quality of life (QOL). Only $32 \%$ of patients suffering sleep disturbance received treatment.

\section{Conclusions}

Sleep disturbance is common in Chinese older patients with T2DM, but the rate of treatment appears low. More aggressive measures should be implemented to improve the assessment and treatment of sleep disturbances in patients with T2DM.

\section{Introduction}

Diabetes is an increasing worldwide public health crisis, affecting $8 \%$ of the adult population worldwide, considered to be the seventh highest cause of premature death in 2016[1]. The International Diabetes Federation (IDF) estimates that there were approximately 463 million patients with diabetes globally in the year 2019, and there will be 578 million adults living with diabetes by 2030 and 700 million by 2045[2]. In China, the overall prevalence of diabetes in adults was estimated to be $11.6 \%[3]$. The global economic burden of treating diabetes is increasing, estimated to be 1.31 trillion USD/y. Diabetes places a substantial economic burden on public health care budget[4], and shortens life expectancy by one third[5].

Sleep disturbances are significantly more common among individuals with DM (Diabetes Mellitus) than in the general population, which may be due to the disease itself or its complications[6]. The pathophysiologic mechanism underlying the association between sleep and DM is likely to be complex and bidirectional. Sleep disturbance might play a role in the drastic increase in diabetes prevalence [7, 8]. In turn, people who already have diabetes suffer from more sleep disturbance than those without diabetes[9]. Several studies supported that glucose control could potentially contribute to sleep disturbance [10]. The combination of those two conditions likely poses a greater threat to an individual's health. Sleep assessment and management for diabetic patients have been incorporated into international clinical practice guidelines.

Depression is common among people with diabetes [11]. Biological mechanisms have been proposed through a dysregulated and overactive HPA axis, a shift in sympathetic nervous system tone toward enhanced sympathetic activity, and a pro-inflammatory state [12]. Laake [13] found that increased inflammation may be involved in the pathogenesis of depression in people with type 2 diabetes, which in turn could contribute to the increased risk of complications and mortality in this clinical population [14].

Diabetes and Quality of Life (QOL) have strong associations in terms of patients' overall health including their psychology, physical well-being, compliance with medication [15]. Research show that QOL of diabetic patients is significantly lower than that of the general population [16]. The importance of developing QOL has been given specific attention [17].

Therefore, the purposes of this study were to investigate (1) the prevalence of sleep disturbances in older diabetic adults in Foshan City, South China; (2) the socio-demographic and clinical correlates of sleep disturbances; (3) the correlation between sleep disturbances, depression, and quality of life (QOL).

\section{Methods}

\section{Ethics Statement}

This was a cross-sectional study initiated by the Guangdong Mental Health Center. The study protocol have been performed in accordance with the Declaration of Helsinki and was approved by the Research Ethics Committee of the Guangdong Provincial People's Hospital, Guangdong Academy of Medical Sciences (Reference number: GDREC2018543H (R1)). Written informed consents were obtained from all participants before the data collection. The participants were assured of the confidentiality of their data.

\section{Study Design and Participants}

This study was carried out in the city of Foshan, South China, from May 2016 to June 2019. Data collection was obtained face-to-face by four trained interviewers using a scale designed for this study during a 40-50 min interview. Basic socio-demographic and clinical characteristics were collected including age, gender, education status, marital status, living condition, family income, and so on. 
The interrater reliability of the judgement of sleep disturbances between the interviewers obtained in examining 20 subjects was satisfactory (kappa values > 0.9).

All subjects were recruited if they were aged 50 years or above, diagnosed as diabetes by endocrinologists, and were able to communicate adequately and comprehend the purpose of the study. In this research, subjects aged 50 years or above were classified as "older adults." The same cutoff point was set in other research too [18].

\section{Data Collection}

Sleep disturbance during the past month was examined targeting three basic forms: "Do you have difficulties in falling sleep?" for difficulty initiating sleep (DIS); "Do you have difficulties in maintaining sleep and wake up often?" for difficulty maintaining sleep (DMS); and "Do you wake up in the midnight or early morning and have difficulties in falling sleep again?" for early morning awakening (EMA). At least one "often" answer to the three questions qualified the participant as "having sleep disturbance." Treatment for sleep disturbances during the past month was also recorded. This assessment of sleep disturbances has also been used in other studies $[19,20]$.

Depressive symptom was measured using Montgomery-Asberg Depression Rating Scale (MADRS) [21]. MADRS is an interviewer-rated instrument, comprising 10 items, each measured on a 6-point scale (scores range from 0-60 with higher scores depicting greater symptom severity).

Quality of Life(QOL)was measured with the Chinese version of the World Health Organization Quality of Life- BREF (WHOQOL-BREF)[22]. The WHOQOL-BREF includes 26 items covering four domains: physical health, psychological health, social relationships, and environmental factors. A higher score reflects better QOL.

\section{Statistical analysis}

Database was setup via the software of EPIData, and the operation about data input was carried by two persons. Then the database was transferred to IBM ${ }^{\circ}$ SPSS ${ }^{\circledR}$ Statistics Version 24 (IBM SPSS Statistics for Windows, IBM Corp, Armonk, NY). The significance level was set at 0.05, two-tailed Student's $t$ tests were employed to compare continuous data between interviewees with and without different type of sleeping disturbance, and Chi square tests were implemented in the nominal and ordinal factors to verify the differences of subsets grouped from the original sample. Confidential intervals of $95 \%$ were calculated in the procedure of binomial tests.

All categorical factors were converted to dummy variables, indicators were specified as following: male, 50s-aged, living with marital spouse, having a religious faith, earning monthly less than or equal to 3000 RMB, illiterate or primary-school level, smoking by now, owning a health insurance. The coefficients of indicators in the model were supposed as zero by default. The pseudo determination coefficients of logistics regressions, Nagelkerke R2, were presented at last.

Quantitative variables and scale scorings were checked by the Shapiro-Wilk test to verify the normality. Chi square tests were performed between subsets with and without any sleep disturbance. Descriptive data are presented as mean values \pm SD. The analyses of Binary Multifactor Logistic Regressions were performed to estimate the relative risk power in form of odd ratios (OR) which equalled natural constant to the power of $B$ (eB).

\section{Results}

There are 195 older adults participated in the study with a response rate of $100 \%$. The frequency of at least one type of sleep disturbance, DIS, DMS, and EMA was $38.5 \%, 23.6 \%, 25.6 \%$ and $26.2 \%$, respectively. The ratio of one, two, and three types of sleep disturbances were $15.9 \%, 8.2 \%$, and $14.4 \%$, respectively. Only $32 \%$ of subjects suffering sleep disturbance received treatment.

Demographic and Clinical Characteristics of the sample were displayed in Table 1. No statistically significant difference was observed in socio-demographic data between participants with and without sleep disturbances except age. Further test indicated that percentage of 70 s age group was different significantly from the others at the 0.05 level. 
Table 1

Demographic and Clinical Characteristics of the Sample (Overall Sample Size $=195$ )

\begin{tabular}{|c|c|c|c|c|c|c|c|c|c|c|}
\hline \multirow[t]{2}{*}{ Demography } & & \multicolumn{2}{|c|}{ Group Size } & \multicolumn{2}{|c|}{$\begin{array}{l}\text { Sleep Disturbance } \\
\text { (Any Type) }\end{array}$} & \multicolumn{2}{|c|}{ No Sleep Disturbance } & \multicolumn{3}{|c|}{ Statistics } \\
\hline & & $\mathrm{N}$ & Percent & $\mathrm{N}$ & Percent & $\mathrm{N}$ & Percent & $x^{2}$ & $D f$ & $p$ \\
\hline \multirow{4}{*}{$\begin{array}{l}\text { Age Group } \\
\text { (Years) }\end{array}$} & $50 s^{*}$ & 67 & $34.4 \%$ & 20 & $26.7 \%$ & 47 & $39.2 \%$ & 11.00 & 3 & 0.01 \\
\hline & $60 s$ & 70 & $35.9 \%$ & 28 & $37.3 \%$ & 42 & $35.0 \%$ & & & \\
\hline & $70 \mathrm{~s}$ & 42 & $21.5 \%$ & 24 & $32.0 \%$ & 18 & $15.0 \%$ & & & \\
\hline & $\geq 80$ & 16 & $8.2 \%$ & 3 & $4.0 \%$ & 13 & $10.8 \%$ & & & \\
\hline \multirow[t]{2}{*}{ Gender } & Male & 97 & $49.7 \%$ & 39 & $52.0 \%$ & 58 & $48.3 \%$ & 0.25 & 1 & 0.62 \\
\hline & Female & 98 & $50.3 \%$ & 36 & $48.0 \%$ & 62 & $51.7 \%$ & & & \\
\hline \multirow[t]{2}{*}{ Living Status } & Living With Marital Spouse & 158 & $81.0 \%$ & 59 & $78.7 \%$ & 99 & $82.5 \%$ & 0.44 & 1 & 0.51 \\
\hline & Alone & 37 & $19.0 \%$ & 16 & $21.3 \%$ & 21 & $17.5 \%$ & & & \\
\hline \multirow[t]{2}{*}{ Education } & Illiteracy or Primary School & 82 & $42.1 \%$ & 32 & $42.7 \%$ & 50 & $41.7 \%$ & 0.02 & 1 & 0.89 \\
\hline & Junior High School and above & 113 & $57.9 \%$ & 43 & $57.3 \%$ & 70 & $58.3 \%$ & & & \\
\hline \multirow[t]{2}{*}{ Religious Beliefs } & Yes & 77 & $39.5 \%$ & 32 & $42.7 \%$ & 45 & $37.5 \%$ & 0.52 & 1 & 0.47 \\
\hline & No & 118 & $60.5 \%$ & 43 & $57.3 \%$ & 75 & $62.5 \%$ & & & \\
\hline \multirow[t]{2}{*}{ Monthly income } & $<=3000 \mathrm{RMB}$ & 86 & $44.1 \%$ & 30 & $40.0 \%$ & 56 & $46.7 \%$ & 0.83 & 1 & 0.36 \\
\hline & $>3000 \mathrm{RMB}$ & 109 & $55.9 \%$ & 45 & $60.0 \%$ & 64 & $53.3 \%$ & & & \\
\hline \multirow[t]{2}{*}{ health insurance } & Any Type & 177 & $91.7 \%$ & 69 & $93.2 \%$ & 108 & $90.8 \%$ & 0.37 & 1 & 0.54 \\
\hline & None & 16 & $8.3 \%$ & 5 & $6.8 \%$ & 11 & $9.2 \%$ & & & \\
\hline
\end{tabular}

Sleep disturbances by sex and age was presented in Table2. The confidence intervals of 95\%, estimated by the way of Clopper-Pearson's EXACT method, were included. In males the prevalence of DIS, DMS and EMA was $21.6 \%, 24.7 \%$, and $24.7 \%$, respectively. And the corresponding figures in females were $25.5 \%$, $26.5 \%$, and $27.6 \%$, respectively.

Table3 displayed relationship between Sleeping Disturbances and MADRS and WHOQOL-BREF. The scores of WHOQOL-BREF and MADRS were significantly relevant to quality of sleeping.

Table2 Prevalence of Sleep Disturbance by Age and Sex (Overall Sample Size $=195$ ) 


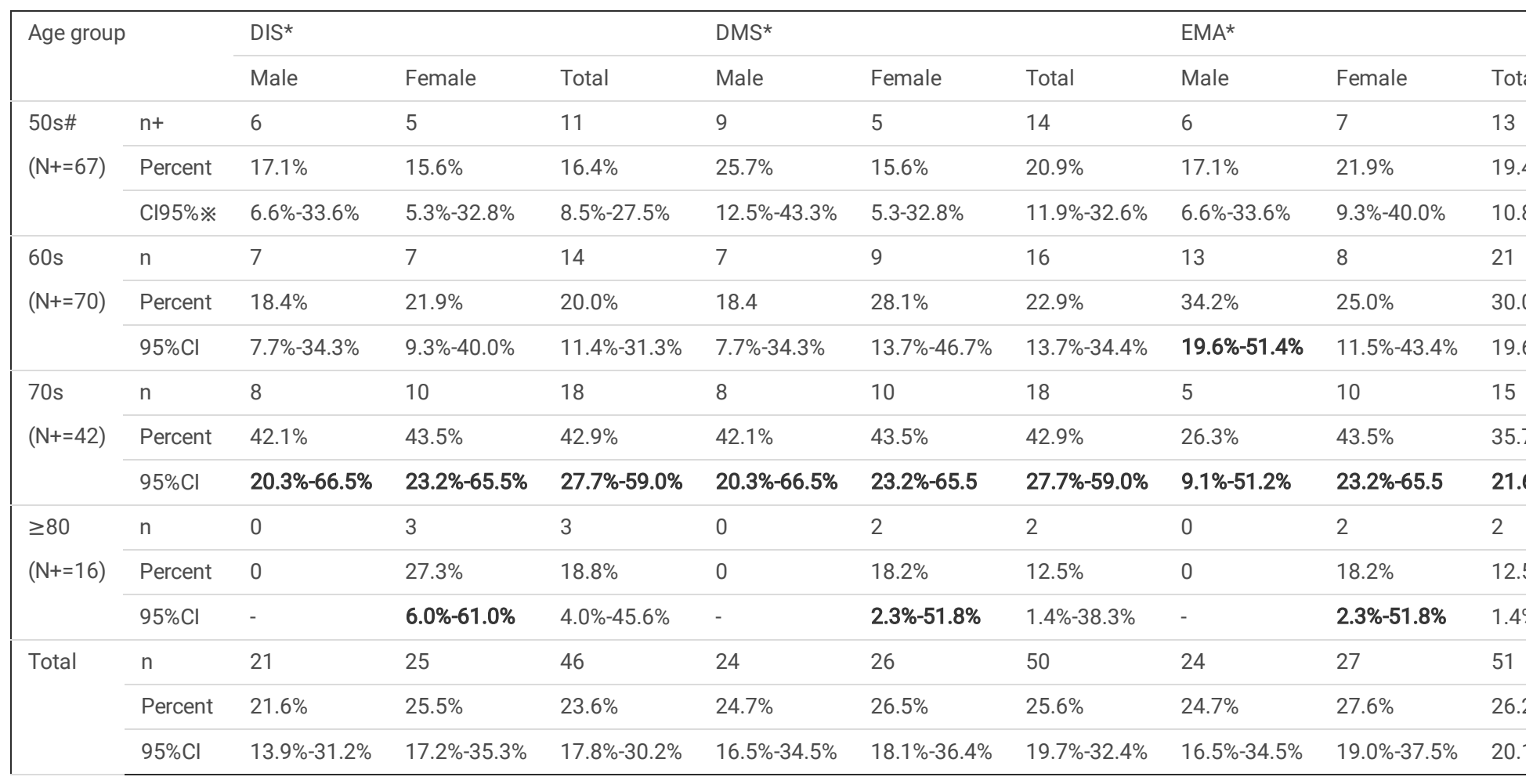

* DIS: Difficulty Initiating Sleep囚 DMS: Difficulty Maintaining Sleep囚 EMA: Early Morning Awakening.

\# 50 s meant that the interviewees were at the age of 50 to 59 , and the similar below.

$+\mathrm{N}$ represented the subset size of each age group, and $\mathrm{n}$ the amount of interviewees complaining of any sleeping disturbance.

Table3 Relationship between Sleeping Disturbances and MADRS and WHOQOL-BREF: ANOVA

\begin{tabular}{|c|c|c|c|c|c|c|c|c|c|c|c|c|c|c|c|c|c|}
\hline \multirow[t]{2}{*}{ Scale } & & \multicolumn{4}{|l|}{ DIS } & \multicolumn{4}{|c|}{ DMS } & \multicolumn{4}{|c|}{ EMA } & \multicolumn{4}{|c|}{ Any Sleep Disturbance } \\
\hline & & $\mathrm{N}$ & Mean & SD & $\mathrm{p}$ & $\mathrm{N}$ & Mean & SD & $\mathrm{p}$ & $\mathrm{N}$ & Mean & SD & $\mathrm{p}$ & $\mathrm{N}$ & Mean & SD & $\mathrm{p}$ \\
\hline \multirow[t]{3}{*}{ MADRS } & Yes & 44 & 13.30 & 10.21 & \multirow[t]{3}{*}{$<0.01$} & 47 & 12.04 & 9.36 & \multirow[t]{3}{*}{$<0.01$} & 49 & 14.08 & 9.68 & \multirow[t]{3}{*}{$<0.01$} & 72 & 11.86 & 9.27 & \multirow[t]{3}{*}{$<0.01$} \\
\hline & No & 135 & 6.40 & 6.80 & & 132 & 6.69 & 7.43 & & 130 & 5.84 & 6.43 & & 107 & 5.56 & 6.47 & \\
\hline & Total & 179 & 8.09 & 8.30 & & 179 & 8.09 & 8.30 & & 179 & 8.09 & 8.30 & & 179 & 8.09 & 8.30 & \\
\hline \multirow{3}{*}{$\begin{array}{l}\text { WHOQOL- } \\
\text { BREF }\end{array}$} & Yes & 46 & 81.91 & 11.02 & \multirow[t]{3}{*}{$<0.01$} & 50 & 81.64 & 10.08 & \multirow[t]{3}{*}{$<0.01$} & 51 & 79.55 & 9.97 & \multirow[t]{3}{*}{$<0.01$} & 75 & 82.16 & 9.59 & \multirow[t]{3}{*}{$<0.01$} \\
\hline & No & 144 & 86.75 & 9.65 & & 140 & 86.99 & 9.88 & & 139 & 87.79 & 9.36 & & 115 & 87.81 & 9.97 & \\
\hline & Total & 190 & 85.58 & 10.18 & & 190 & 85.58 & 10.18 & & 190 & 85.58 & 10.18 & & 190 & 85.58 & 10.18 & \\
\hline
\end{tabular}

*yes: diagnosed with sleep disturbances

no: diagnosed without sleep disturbances

Table 4 showed the independent relationships between each type of sleep disturbance and the socio-demographic and clinical characteristics. Advanced age, more severe depressive symptoms and female independently contributed to sleep disturbance. 
Table 4

Correlations Between Multiple Factors and Sleep Disturbances: Binary Logistic Regression

\begin{tabular}{|c|c|c|c|c|c|c|c|c|c|c|c|c|c|c|c|c|}
\hline \multirow[t]{2}{*}{ Multi-Factors } & & \multicolumn{5}{|l|}{ DIS } & \multicolumn{5}{|l|}{ DMS } & \multicolumn{5}{|l|}{ EMA } \\
\hline & & $B$ & $S E$ & $p$ & $O R^{*}$ & $C / 95 \%$ & $B$ & $S E$ & $p$ & $O R^{*}$ & Cl95\% & $B$ & $S E$ & $p$ & $O R^{*}$ & C195\% \\
\hline Gender & Female & -0.05 & 0.54 & 0.92 & 0.95 & $\begin{array}{l}0.33- \\
2.74\end{array}$ & -0.26 & 0.50 & 0.60 & 0.77 & $\begin{array}{l}0.29- \\
2.06\end{array}$ & -1.21 & 0.56 & 0.03 & 0.30 & $\begin{array}{l}0.10- \\
0.89\end{array}$ \\
\hline \multirow[t]{3}{*}{ Age Group } & $60 s$ & 0.28 & 0.57 & 0.62 & 1.33 & $\begin{array}{l}0.44- \\
4.02\end{array}$ & 0.08 & 0.51 & 0.88 & 1.08 & $\begin{array}{l}0.40- \\
2.95\end{array}$ & 0.85 & 0.53 & 0.11 & 2.33 & $\begin{array}{l}0.82- \\
6.63\end{array}$ \\
\hline & $70 \mathrm{~s}$ & 1.20 & 0.59 & 0.04 & 3.33 & $\begin{array}{l}1.06- \\
10.48\end{array}$ & 0.82 & 0.55 & 0.14 & 2.26 & $\begin{array}{l}0.77- \\
6.61\end{array}$ & 0.35 & 0.60 & 0.56 & 1.41 & $\begin{array}{l}0.44- \\
4.55\end{array}$ \\
\hline & $\geq 80$ & 0.25 & 0.94 & 0.79 & 1.29 & $\begin{array}{l}0.20- \\
8.16\end{array}$ & -0.52 & 1.01 & 0.61 & 0.60 & $\begin{array}{l}0.08- \\
4.33\end{array}$ & -1.62 & 1.26 & 0.20 & 0.20 & $\begin{array}{l}0.02- \\
2.33\end{array}$ \\
\hline $\begin{array}{l}\text { Living With } \\
\text { Marital } \\
\text { Spouse }\end{array}$ & No & -0.93 & 0.67 & 0.17 & 0.40 & $\begin{array}{l}0.11- \\
1.48\end{array}$ & -1.03 & 0.65 & 0.11 & 0.36 & $\begin{array}{l}0.10- \\
1.27\end{array}$ & 0.73 & 0.65 & 0.26 & 2.07 & $\begin{array}{l}0.59- \\
7.33\end{array}$ \\
\hline $\begin{array}{l}\text { Any Religious } \\
\text { Faith }\end{array}$ & No & 0.43 & 0.46 & 0.35 & 1.53 & $\begin{array}{l}0.63- \\
3.76\end{array}$ & 0.06 & 0.42 & 0.89 & 1.06 & $\begin{array}{l}0.47- \\
2.42\end{array}$ & -0.30 & 0.45 & 0.51 & 0.74 & $\begin{array}{l}0.31- \\
1.78\end{array}$ \\
\hline $\begin{array}{l}\text { Monthly } \\
\text { Income(RMB) }\end{array}$ & $>3000$ & 1.14 & 0.53 & 0.03 & 3.11 & $\begin{array}{l}1.10- \\
8.84\end{array}$ & 0.32 & 0.49 & 0.51 & 1.38 & $\begin{array}{l}0.53- \\
3.60\end{array}$ & -0.17 & 0.51 & 0.75 & 0.85 & $\begin{array}{l}0.31- \\
2.31\end{array}$ \\
\hline $\begin{array}{l}\text { Primary } \\
\text { school level } \\
\text { or illiterate }\end{array}$ & No & -0.40 & 0.48 & 0.40 & 0.67 & $\begin{array}{l}0.26- \\
1.71\end{array}$ & -0.25 & 0.45 & 0.58 & 0.78 & $\begin{array}{l}0.32- \\
1.88\end{array}$ & -0.35 & 0.47 & 0.46 & 0.71 & $\begin{array}{l}0.28- \\
1.77\end{array}$ \\
\hline $\begin{array}{l}\text { Smoking } \\
\text { Habit at } \\
\text { Present }\end{array}$ & No & 0.21 & 0.68 & 0.76 & 1.23 & $\begin{array}{l}0.33- \\
4.65\end{array}$ & 0.46 & 0.65 & 0.48 & 1.59 & $\begin{array}{l}0.45- \\
5.61\end{array}$ & 0.50 & 0.67 & 0.45 & 1.65 & $\begin{array}{l}0.45- \\
6.09\end{array}$ \\
\hline $\begin{array}{l}\text { Any Health } \\
\text { Insurance }\end{array}$ & No & -0.31 & 0.50 & 0.54 & 0.73 & $\begin{array}{l}0.27- \\
1.96\end{array}$ & -0.10 & 0.46 & 0.84 & 0.91 & $\begin{array}{l}0.37- \\
2.23\end{array}$ & -0.96 & 0.51 & 0.06 & 0.38 & $\begin{array}{l}0.14- \\
1.03\end{array}$ \\
\hline MADRS & & 0.13 & 0.03 & $<0.001$ & 1.13 & $\begin{array}{l}1.07- \\
1.20\end{array}$ & 0.09 & 0.03 & $<0.001$ & 1.10 & $\begin{array}{l}1.04- \\
1.16\end{array}$ & 0.16 & 0.03 & $<0.001$ & 1.17 & $\begin{array}{l}1.10- \\
1.25\end{array}$ \\
\hline Pseudo-R ${ }^{2}$ & & 0.36 & & & & & 0.29 & & & & & 0.42 & & & & \\
\hline
\end{tabular}

\section{Discussion}

Within the realm of sleep research, the term "sleep disorder" is more common than the term "sleep disturbance". These two terms are different and should not be used interchangeably. Sleep disorder is diagnosed, using strict criteria, and may be classified into distinct categories, such as insomnia and sleep disorder. The term "sleep disturbance" in the context of diabetes was first mentioned in 1992[23], mainly used to represent insomnia symptoms, might be universally experienced by anyone at some point in their lives. Sleep disturbance was most commonly characterized by difficulty initiating sleep (DIS), difficulty maintaining sleep (DMS)[24-27], and early morning awakening (EMA).

According to an internet survey of over 7 thousand people in the United States with T2D, three-quarters of participants suffered from sleep symptoms, and one-quarter of them were actually diagnosed with a sleep disorder [28]. A study in Ethiopia showed that about $55.6 \%$ of diabetic patients were affected by sleep disturbance [29]. Other research revealed that the prevalence of sleep disturbance in people with T2DM ranged from 55-71\% [30, 31]. In this study, the prevalence of DIS, DMS, EMA and any type sleep disturbance was $23.6 \%, 25.6 \%, 26.2 \%$ and $38.5 \%$, respectively. The finding of this study was lower than studies above maybe due to the different social-cultural backgrounds. In Chinese society, having mental disorders is a shame [32]. Mental diseases, including sleep disturbance, is considered a stigma for many Chinese, which leads to low medical service utilization and treatment [33]. An epidemiological study of 4596 individuals aged 18 years or above living in Beijing, China found that people believed that most members of their society have negative attitudes towards people with mental disorders [34]. Stigma of mental disorders is a barrier and may prevent people seeking [35, 36]. And our study also found that only $32 \%$ of patients suffering sleep disturbance received treatment. On the other hand, due to the worry concerns related to drug dependence and side effects, patients often choose non-pharmacological treatments [37]. Acupuncture, as an important component of traditional Chinese medicine (TCM), has been widely applied to treat sleep disturbances[38]. In this study, $15.8 \%$ of people in the non- sleep disturbance group used a sleep aid occasionally, including Chinese herbal medicine and acupuncture, to improve their sleep. Maybe that's why some people did not report their sleep disturbances.

Research revealed that sleep disturbances have a negative impact on glucose metabolism [39] and there's a U-shape association between short and long sleep duration in individuals identified as risk factors for developing T2DM [8,40,41]. Sleep duration of less than $6 \mathrm{~h}$ or $>9 \mathrm{~h}$ is associated with increased cardiometabolic risk in people with T2DM [42]. Previous research also found that people with T2DM with approximately $39 \%$ sleeping less than $6.5 \mathrm{~h}$ per night [43]. In this study, the average sleep time was 5.7 hours in sleep disturbance group and 6.86 hours in non-sleep disturbance group, suggested that shorter sleep time was more closely related to diabetes. In this trial, we also found that incidence of sleep disturbances increases with age, which is consistent with previous studies [44-46].

Depressive symptoms in people with diabetes can have a detrimental impact on engagement with diabetes management, and on glycemic control [47], as well as on health-related outcomes [48]. Adults with diabetes are more likely to report significant depressive symptoms than those without diabetes [49]. The 
estimated incidence of clinically significant depressive symptoms among adults with diabetes was 10.6 to $50.6 \%$ [49, 50]. And the association between depression and sleep disturbance is close [51,52]. As such, the high prevalence of this comorbidity is accompanied by high rates of morbidity and mortality worldwide [53]. In this study, depressive symptom in the sleep disturbance group was more obvious than that of those without sleep disturbance, and the more symptoms of sleep disturbance, the more severe depressive symptoms.

Sleep disturbance is one of the factors impairing QOL in people with T2D [54-58], and posing an increased financial burden to both individuals and society $[59,60]$. Diabetes and depression can also seriously affect an individual's quality of life [61]. Reports show that the QOL of people with diabetes is lower than that of people without diabetes [28,62-66]. In this study, we also found that QOL in the sleep disturbance group was worse than that of those without sleep disturbance, and the more symptoms of sleep disturbance, the worse QOL. Our study also found the aging population will have a negative impact on QOL, which is consistent with previous study [67].

\section{Conclusion}

Sleep disturbance is common in Chinese older patients with T2DM, but the rate of treatment appears low. Sleep disturbance is related to depression and decreased quality of life in patients with T2DM. More aggressive measures should be implemented to improve the assessment and treatment of sleep disturbances in patients with T2DM.

\section{Limitations and Future Lines of Research}

The present study has several limitations. Firstly, only subjective sleep measure was used in this study, recall bias could affect research results. Objective sleep assessment should be added to future research. Secondly, the small sample size and convenience sampling limited the generalizability of the study findings. Thirdly, more information related to sleep disturbances, such as blood-glucose levels, complications, should have been collected.

\section{Declarations}

Ethics approval and consent were approved by the Research Ethics Committee of the Guangdong Provincial People's Hospital, Guangdong Academy of Medical Sciences (Reference number: GDREC2018543H (R1)). (Reference number: GDREC2018543H (R1)). Written informed consents were obtained from all participants before the data collection. The participants were assured of the confidentiality of their data.

Confirmation: We confirmed that the study protocol and all methods have been performed in accordance with the relevant guidelines and regulations in the Declaration of Helsinki.

Availability of data and materials: The datasets used and/or analysed during the current study are available from the corresponding author on reasonable request.

Competing interests: The authors declare that they have no conflict of interest in regard to this work.

Funding: Natural Science Foundation of Guangdong Province (No.: 2018A03013816) supported this study in the design of the study and collection, analysis, and interpretation of data and in writing the manuscript.

Authors' contributions: Hou CL and Gong YX analyzed and interpreted the patient data regarding sleep disturbance and type 2 diabetes. Gong YX was a major contributor in writing the manuscript. FU-Jun Jia designed this study. Huang ZH, Wang F, and Yang JJ were responsible for sample collection and psychological evaluation. Wang SB participated in statistical analysis of data and prepared the tables. All authors read and approved the final manuscript.

Acknowledgements: Thank the Endocrinology Department of Foshan first people's Hospital for its strong support for this study.

\section{References}

1. Cho NH, Shaw JE, Karuranga S, Huang Y, da Rocha Fernandes JD, Ohlrogge AW, Malanda B: IDF Diabetes Atlas: Global estimates of diabetes prevalence for 2017 and projections for 2045. Diabetes research and clinical practice 2018, 138:271-281.

2. Saeedi P, Petersohn I, Salpea P, Malanda B, Karuranga S, Unwin N, Colagiuri S, Guariguata L, Motala AA, Ogurtsova K et al: Global and regional diabetes prevalence estimates for 2019 and projections for 2030 and 2045: Results from the International Diabetes Federation Diabetes Atlas, 9(th) edition. Diabetes research and clinical practice $2019,157: 107843$.

3. Xu Y, Wang L, He J, Bi Y, Li M, Wang T, Wang L, Jiang Y, Dai M, Lu J et al: Prevalence and control of diabetes in Chinese adults. Jama 2013, 310(9):948959.

4. Ettaro L, Songer TJ, Zhang P, Engelgau MM: Cost-of-illness studies in diabetes mellitus. PharmacoEconomics 2004, 22(3):149-164.

5. Ahmann AJ: Guidelines and performance measures for diabetes. The American journal of managed care 2007, 13 Suppl 2:S41-46.

6. Khandelwal D, Dutta D, Chittawar S, Kalra S: Sleep Disorders in Type 2 Diabetes. Indian journal of endocrinology and metabolism 2017, 21(5):758-761.

7. Anothaisintawee T, Reutrakul S, Van Cauter E, Thakkinstian A: Sleep disturbances compared to traditional risk factors for diabetes development: Systematic review and meta-analysis. Sleep medicine reviews 2016, 30:11-24.

8. Shan Z, Ma H, Xie M, Yan P, Guo Y, Bao W, Rong Y, Jackson CL, Hu FB, Liu L: Sleep duration and risk of type 2 diabetes: a meta-analysis of prospective studies. Diabetes care 2015, 38(3):529-537. 
9. Keskin A, Ünalacak M, Bilge U, Yildiz P, Güler S, Selçuk EB, Bilgin M: Effects of Sleep Disorders on Hemoglobin A1c Levels in Type 2 Diabetic Patients. Chinese medical journal 2015, 128(24):3292-3297.

10. Barnard K, James J, Kerr D, Adolfsson P, Runion A, Serbedzija G: Impact of Chronic Sleep Disturbance for People Living With T1 Diabetes. Journal of diabetes science and technology 2016, 10(3):762-767.

11. Beydoun MA, Wang Y: Pathways linking socioeconomic status to obesity through depression and lifestyle factors among young US adults. Journal of affective disorders 2010, 123(1-3):52-63.

12. Joseph JJ, Golden SH: Cortisol dysregulation: the bidirectional link between stress, depression, and type 2 diabetes mellitus. Annals of the New York Academy of Sciences 2017, 1391(1):20-34.

13. Laake JP, StahI D, Amiel SA, Petrak F, Sherwood RA, Pickup JC, Ismail K: The association between depressive symptoms and systemic inflammation in people with type 2 diabetes: findings from the South London Diabetes Study. Diabetes care 2014, 37(8):2186-2192.

14. Geraets AFJ, Köhler S, Muzambi R, Schalkwijk CG, Oenema A, Eussen S, Dagnelie PC, Stehouwer CDA, Schaper NC, Henry RMA et al: The association of hyperglycaemia and insulin resistance with incident depressive symptoms over 4 years of follow-up: The Maastricht Study. Diabetologia 2020, 63(11):2315-2328.

15. Hilliard ME, Goeke-Morey M, Cogen FR, Henderson C, Streisand R: Predictors of diabetes-related quality of life after transitioning to the insulin pump. Journal of pediatric psychology 2009, 34(2):137-146.

16. Schram MT, Baan CA, Pouwer F: Depression and quality of life in patients with diabetes: a systematic review from the European depression in diabetes (EDID) research consortium. Current diabetes reviews 2009, 5(2):112-119.

17. Trikkalinou A, Papazafiropoulou AK, Melidonis A: Type 2 diabetes and quality of life. World journal of diabetes 2017, 8(4):120-129.

18. Xiang YT, Li Y, Correll CU, Ungvari GS, Chiu HF, Lai KY, Tang QS, Hao W, Si TM, Wang CY et al: Common use of high doses of antipsychotic medications in older Asian patients with schizophrenia (2001-2009). International journal of geriatric psychiatry 2014, 29(4):359-366.

19. Guo L, Deng J, He Y, Deng X, Huang J, Huang G, Gao X, Lu C: Prevalence and correlates of sleep disturbance and depressive symptoms among Chinese adolescents: a cross-sectional survey study. BMJ open 2014, 4(7):e005517.

20. Liu X, Zhou H: Sleep duration, insomnia and behavioral problems among Chinese adolescents. Psychiatry research 2002, 111(1):75-85.

21. Montgomery SA, Asberg M: A new depression scale designed to be sensitive to change. The British journal of psychiatry: the journal of mental science $1979,134: 382-389$.

22. Development of the World Health Organization WHOQOL-BREF quality of life assessment. The WHOQOL Group. Psychological medicine 1998, 28(3):551-558.

23. Bendtson I, Gade J, Thomsen CE, Rosenfalck A, Wildschiødtz G: Sleep disturbances in IDDM patients with nocturnal hypoglycemia. Sleep 1992, 15(1):7481.

24. Izci-Balserak B, Pien GW: The relationship and potential mechanistic pathways between sleep disturbances and maternal hyperglycemia. Current diabetes reports 2014, 14(2):459.

25. Knutson KL, Van Cauter E, Zee P, Liu K, Lauderdale DS: Cross-sectional associations between measures of sleep and markers of glucose metabolism among subjects with and without diabetes: the Coronary Artery Risk Development in Young Adults (CARDIA) Sleep Study. Diabetes care 2011, 34(5):1171-1176

26. Reutrakul S, Van Cauter E: Interactions between sleep, circadian function, and glucose metabolism: implications for risk and severity of diabetes. Annals of the New York Academy of Sciences 2014, 1311:151-173.

27. Cappuccio FP, D'Elia L, Strazzullo P, Miller MA: Quantity and quality of sleep and incidence of type 2 diabetes: a systematic review and meta-analysis. Diabetes care 2010, 33(2):414-420.

28. Gupta S, Wang Z: Predictors of sleep disorders among patients with type 2 diabetes mellitus. Diabetes \& metabolic syndrome 2016, 10(4):213-220.

29. Jemere T, Mossie A, Berhanu H, Yeshaw Y: Poor sleep quality and its predictors among type 2 diabetes mellitus patients attending Jimma University Medical Center, Jimma, Ethiopia. BMC research notes 2019, 12(1):488.

30. Luyster FS, Dunbar-Jacob J: Sleep quality and quality of life in adults with type 2 diabetes. The Diabetes educator 2011, 37(3):347-355.

31. Knutson KL, Ryden AM, Mander BA, Van Cauter E: Role of sleep duration and quality in the risk and severity of type 2 diabetes mellitus. Archives of internal medicine 2006, 166(16):1768-1774.

32. Tsang HW, Angell B, Corrigan PW, Lee YT, Shi K, Lam CS, Jin S, Fung KM: A cross-cultural study of employers' concerns about hiring people with psychotic disorder: implications for recovery. Social psychiatry and psychiatric epidemiology 2007, 42(9):723-733.

33. Lauber C, Rössler W: Stigma towards people with mental illness in developing countries in Asia. International review of psychiatry (Abingdon, England) 2007, 19(2):157-178.

34. Liu J, Yan F, Ma X, Guo HL, Tang YL, Rakofsky JJ, Wu XM, Li XQ, Zhu H, Guo XB et al: Perceptions of public attitudes towards persons with mental illness in Beijing, China: results from a representative survey. Social psychiatry and psychiatric epidemiology 2016, 51(3):443-453.

35. Angermeyer MC, van der Auwera S, Carta MG, Schomerus G: Public attitudes towards psychiatry and psychiatric treatment at the beginning of the 21st century: a systematic review and meta-analysis of population surveys. World psychiatry: official journal of the World Psychiatric Association (WPA) 2017, 16(1):50-61.

36. Chen JA, Shapero BG, Trinh NT, Chang TE, Parkin S, Alpert JE, Fava M, Yeung AS: Association Between Stigma and Depression Outcomes Among Chinese Immigrants in a Primary Care Setting. The Journal of clinical psychiatry 2016, 77(10):e1287-e1292. 
37. Vincent N, Lionberg C: Treatment preference and patient satisfaction in chronic insomnia. Sleep 2001, 24(4):411-417.

38. Kaptchuk TJ: Acupuncture: theory, efficacy, and practice. Annals of internal medicine 2002, 136(5):374-383.

39. Strand LB, Carnethon M, Biggs ML, Djoussé L, Kaplan RC, Siscovick DS, Robbins JA, Redline S, Patel SR, Janszky I et al: Sleep Disturbances and Glucose Metabolism in Older Adults: The Cardiovascular Health Study. Diabetes care 2015, 38(11):2050-2058.

40. Bajaj S: RSSDI clinical practice recommendations for the management of type 2 diabetes mellitus 2017. International journal of diabetes in developing countries 2018, 38(Suppl 1):1-115.

41. Haneda M, Noda M, Origasa H, Noto H, Yabe D, Fujita Y, Goto A, Kondo T, Araki E: Japanese Clinical Practice Guideline for Diabetes 2016. Diabetology international 2018, 9(1):1-45.

42. Cooper AJ, Westgate K, Brage S, Prevost AT, Griffin SJ, Simmons RK: Sleep duration and cardiometabolic risk factors among individuals with type 2 diabetes. Sleep medicine 2015, 16(1):119-125.

43. Ohkuma T, Fujii H, Iwase M, Ogata-Kaizu S, Ide H, Kikuchi Y, Idewaki Y, Jodai T, Hirakawa Y, Nakamura U et al: U-shaped association of sleep duration with metabolic syndrome and insulin resistance in patients with type 2 diabetes: the Fukuoka Diabetes Registry. Metabolism: clinical and experimental2014, 63(4):484-491.

44. Nowicki Z, Grabowski K, Cubała WJ, Nowicka-Sauer K, Zdrojewski T, Rutkowski M, Bandosz P: Prevalence of self-reported insomnia in general population of Poland. Psychiatria polska 2016, 50(1):165-173.

45. Li J, Vitiello MV, Gooneratne NS: Sleep in Normal Aging. Sleep Med Clin 2018, 13(1):1-11.

46. Gulia KK, Kumar VM: Sleep disorders in the elderly: a growing challenge. Psychogeriatrics: the official journal of the Japanese Psychogeriatric Society 2018, 18(3):155-165.

47. Lustman PJ, Anderson RJ, Freedland KE, de Groot M, Carney RM, Clouse RE: Depression and poor glycemic control: a meta-analytic review of the literature. Diabetes care 2000, 23(7):934-942.

48. Black SA, Markides KS, Ray LA: Depression predicts increased incidence of adverse health outcomes in older Mexican Americans with type 2 diabetes. Diabetes care 2003, 26(10):2822-2828.

49. Wang Y, Lopez JM, Bolge SC, Zhu VJ, Stang PE: Depression among people with type 2 diabetes mellitus, US National Health and Nutrition Examination Survey (NHANES), 2005-2012. BMC psychiatry 2016, 16:88.

50. Ali S, Stone MA, Peters JL, Davies MJ, Khunti K: The prevalence of co-morbid depression in adults with Type 2 diabetes: a systematic review and metaanalysis. Diabetic medicine: a journal of the British Diabetic Association 2006, 23(11):1165-1173.

51. Taylor DJ, Lichstein KL, Durrence HH: Insomnia as a health risk factor. Behavioral sleep medicine 2003, 1(4):227-247.

52. Suh S, Kim H, Yang HC, Cho ER, Lee SK, Shin C: Longitudinal course of depression scores with and without insomnia in non-depressed individuals: a 6year follow-up longitudinal study in a Korean cohort. Sleep 2013, 36(3):369-376.

53. Nouwen A, Adriaanse MC, van Dam K, Iversen MM, Viechtbauer W, Peyrot M, Caramlau I, Kokoszka A, Kanc K, de Groot M et al: Longitudinal associations between depression and diabetes complications: a systematic review and meta-analysis. Diabetic medicine: a journal of the British Diabetic Association 2019, 36(12):1562-1572.

54. Barakat S, Abujbara M, Banimustafa R, Batieha A, Ajlouni K: Sleep Quality in Patients With Type 2 Diabetes Mellitus. Journal of clinical medicine research 2019, 11(4):261-266.

55. Rongve A, Boeve BF, Aarsland D: Frequency and correlates of caregiver-reported sleep disturbances in a sample of persons with early dementia. Journal of the American Geriatrics Society 2010, 58(3):480-486.

56. Marion MH, Qurashi M, Marshall G, Foster O: Is REM sleep behaviour disorder (RBD) a risk factor of dementia in idiopathic Parkinson's disease? Journal of neurology 2008, 255(2):192-196.

57. Naismith SL, Rogers NL, Lewis SJ, Terpening Z, Ip T, Diamond K, Norrie L, Hickie IB: Sleep disturbance relates to neuropsychological functioning in late-life depression. Journal of affective disorders 2011, 132(1-2):139-145.

58. Naismith SL, Hickie IB, Lewis SJ: The role of mild depression in sleep disturbance and quality of life in Parkinson's disease. The Journal of neuropsychiatry and clinical neurosciences 2010, 22(4):384-389.

59. Strand LB, Tsai MK, Gunnell D, Janszky I, Wen CP, Chang SS: Self-reported sleep duration and coronary heart disease mortality: A large cohort study of 400,000 Taiwanese adults. International journal of cardiology 2016, 207:246-251.

60. Knutson KL: Sleep duration and cardiometabolic risk: a review of the epidemiologic evidence. Best practice \& research Clinical endocrinology \& metabolism 2010, 24(5):731-743.

61. Renn BN, Feliciano L, Segal DL: The bidirectional relationship of depression and diabetes: a systematic review. Clinical psychology review 2011, 31(8):1239-1246.

62. Rubin RR, Peyrot M: Quality of life and diabetes. Diabetes/metabolism research and reviews 1999, 15(3):205-218.

63. Sakamoto R, Yamakawa T, Takahashi K, Suzuki J, Shinoda MM, Sakamaki K, Danno H, Tsuchiya H, Waseda M, Takano T et al: Association of usual sleep quality and glycemic control in type 2 diabetes in Japanese: A cross sectional study. Sleep and Food Registry in Kanagawa (SOREKA). PloS one 2018, 13(1):e0191771.

64. Lou P, Qin Y, Zhang P, Chen P, Zhang L, Chang G, Li T, Qiao C, Zhang N: Association of sleep quality and quality of life in type 2 diabetes mellitus: a crosssectional study in China. Diabetes research and clinical practice 2015, 107(1):69-76. 
65. Zeng Y, Wu J, Yin J, Chen J, Yang S, Fang Y: Association of the combination of sleep duration and sleep quality with quality of life in type 2 diabetes patients. Quality of life research: an international journal of quality of life aspects of treatment, care and rehabilitation 2018, 27(12):3123-3130.

66. Bani-Issa W, Al-Shujairi AM, Patrick L: Association between quality of sleep and health-related quality of life in persons with diabetes mellitus type 2 . $J$ Clin Nurs 2018, 27(7-8):1653-1661.

67. Mata-Cases M, Casajuana M, Franch-Nadal J, Casellas A, Castell C, Vinagre I, Mauricio D, Bolíbar B: Direct medical costs attributable to type 2 diabetes mellitus: a population-based study in Catalonia, Spain. The European journal of health economics: HEPAC : health economics in prevention and care 2016, 17(8):1001-1010. 